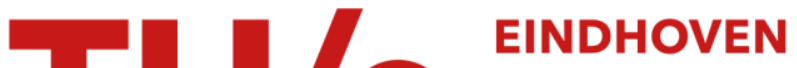 UNIVERSITY OF TECHNOLOGY
}

\section{Mode-locked lasers in InP photonic integrated circuits}

\section{Citation for published version (APA):}

Bente, E. A. J. M., Latkowski, S., Moskalenko, V., Llorens Revull, M., Tahvili, M. S., \& Williams, K. A. (2017). Mode-locked lasers in InP photonic integrated circuits. In A. Belyanin, \& P. Smowton (Eds.), Novel In-Plane Semiconductor Lasers XVI (pp. 1-7). [101230F] (Proceedings of SPIE - The International Society for Optical Engineering; Vol. 10123). SPIE. https://doi.org/10.1117/12.2251469

DOI:

10.1117/12.2251469

Document status and date:

Published: 20/02/2017

\section{Document Version:}

Author's version before peer-review

\section{Please check the document version of this publication:}

- A submitted manuscript is the version of the article upon submission and before peer-review. There can be important differences between the submitted version and the official published version of record. People interested in the research are advised to contact the author for the final version of the publication, or visit the $\mathrm{DOI}$ to the publisher's website.

- The final author version and the galley proof are versions of the publication after peer review.

- The final published version features the final layout of the paper including the volume, issue and page numbers.

Link to publication

\section{General rights}

Copyright and moral rights for the publications made accessible in the public portal are retained by the authors and/or other copyright owners and it is a condition of accessing publications that users recognise and abide by the legal requirements associated with these rights.

- Users may download and print one copy of any publication from the public portal for the purpose of private study or research.

- You may not further distribute the material or use it for any profit-making activity or commercial gain

- You may freely distribute the URL identifying the publication in the public portal.

If the publication is distributed under the terms of Article 25fa of the Dutch Copyright Act, indicated by the "Taverne" license above, please follow below link for the End User Agreement:

www.tue.nl/taverne

Take down policy

If you believe that this document breaches copyright please contact us at:

openaccess@tue.nl

providing details and we will investigate your claim. 


\title{
Mode-locked lasers in InP photonic integrated circuits
}

\author{
Erwin Bente, Sylwester Latkowski, Valentina Moskalenko, \\ Mònica Llorens-Revull, Saeed Tahvili, Kevin Williams \\ Institute for Photonic Integration, Eindhoven University of Technology, \\ PO Box 513, $5600 \mathrm{MB}$, Eindhoven, the Netherlands
}

\begin{abstract}
In this paper an overview is presented of results obtained with mode-locked semiconductor laser systems that are monolithically integrated using a standardized photonic integration platform based on InP. The laser systems are operating around 1550nm. In this technology platform the basic components that form the laser circuits such as amplifiers, passive waveguides and filters, as well as the semiconductor processing are standardized. Several of the possibilities that such a standardized technology offer are demonstrated by a number of examples of realized devices such as low repetition rate mode-locked lasers, a stabilized comb system and a wide frequency comb source.
\end{abstract}

Keywords: mode-locked lasers, semiconductor lasers, photonic integrated circuits

\section{INTRODUCTION}

Short optical pulses and wide coherent optical frequency combs generated by mode-locked lasers have found applications in microwave photonics, communication, biophotonics, metrology and machining as well as in many research activities. Typically these applications have been demonstrated using solid state mode-locked laser (MLL) systems e.g. fiber laser or Titanium:sapphire laser systems ${ }^{1}$ or optically pumped semiconductor lasers ${ }^{2}$. Such systems can be flexible and this flexibility is used to meet the widely varying requirements for the laser systems in the different applications. However these systems are also bulky and expensive, so many of the applications which exist could possibly be much more widespread if mass-producible semiconductor devices could provide the required optical output. It is therefore of interest to investigate in how far one can meet application requirements using a photonic integration technology platform where one can design and realize semiconductor laser systems that can contain many standardized elements such as optical amplifiers (SOA), (electro-optic) phase modulators, low-loss passive waveguides, on-chip mirrors, splitters and filters ${ }^{3}$. These capabilities provide a freedom in the design of planar integrated mode-locked laser sources which is similar to that using bulk optics. The additional advantages are stability of the optical paths and compactness. It is likely however that such systems will be less of a general purpose solution.

The interest in semiconductor mode-locked lasers started from the idea that the wide gain spectrum should enable modelocked operation producing femtosecond pulses. Much work on passively mode-locked lasers was done using FabryPerot cavity semiconductor lasers with a single transverse mode waveguide and cleaved facets, typically using a saturable absorber (SA) ${ }^{4}$. A wide range of materials and wavelengths have been investigated over the years. In this work the focus is on lasers operating around the $1550 \mathrm{~nm}$ telecommunication wavelengths and using multi-quantum well material (QW) based on the InGaAsP/InP system. Mode-locked operation is achieved using a saturable absorber (SA). It is instructive to discuss the most simple of such devices, a two section Fabry-Perot laser, in more detail. The waveguide in these lasers has an optical amplifier layer stack throughout, i.e. a so called all-active device. The waveguide is divided into two sections: one long SOA section which is forward biased for the generation and amplification of the light; one much shorter section near one of the facets that is typically reverse biased to provide a SA. The absorption of the SA recovers on a time scale that is longer that the duration of a pulse of a few picoseconds. The saturation of the SA by the front of the pulse and the saturation of the SOA by the first half of the pulse combined makes that a short pulse travelling through the cavity experiences a higher roundtrip gain. This is called slow saturable absorber mode-locking ${ }^{5}$. Such allactive monolithic two-section InP based QW devices have shown a relatively small coherent optical bandwidth (3-5 nm, much smaller than the gain bandwidth), relatively broad pulses of several ps, small ranges of operating conditions, i.e. SOA current and SA voltage for mode-locking and limited average and peak output power. Much better results had been 
obtained using devices with extended cavities in free space or using hybrid integration ${ }^{6,7}$ which is already an indication that much improved performance may be obtained using active/passive photonic integration technology.

There are a number of aspects that have been observed and give rise to limitation in the performance of the two-section all active QW devices. These aspects also have to be taken into account in more advanced devices. The first that in slowsaturable absorber mode-locking the SOA goes into saturation during the pulse. This means a significant change in the carrier density which through the dependency of the refractive index on the carrier density gives rise to self-phase modulation (SPM) on the pulse. This in particular limits the operating range and makes that the pulse will for most conditions not be Fourier limited, the optical output spectrum will be asymmetric and will have one or more dips.

The reshaping of the pulse in the SA and SOA is dependent on the energy in the pulse and that makes that the transit time of the pulse through the SA and SOA is dependent on the pulse energy. This in turn makes that the round-trip time/repetition rate of the laser depends on the energy in the pulse ${ }^{5,8}$. Any amplitude noise will also show up as timing jitter in the output pulse train.

The change in carrier density in the SA by the pulse can be significantly larger than that in the SOA. This means that the current density will be significantly higher in the SA than in the SOA causing heating effects and this will shift the absorption spectrum. E.g. we have observed up to $20 \mathrm{kA} / \mathrm{cm}^{2}$ average current density in an SA. It is difficult to predict at what wavelength the laser will start to lase, it is a balance between the SA absorption spectrum and the SOA gain spectrum. The absorption spectrum in the SA is highly wavelength dependent, more so than the SOA gain spectrum. So the spectrum will change with SA voltage and power level of the laser.

An aspect that is often overlooked in the operation of the laser is the effect of the connections to the laser. The SA in particular is a pulsed current source. The detailed behavior of the SA depends on how the RF signal that originates from it is dealt with. The capacitance, resistance and inductance of the SA (junction, contact pad, cabling) all can affect the operation and can actually be used to the benefit of the laser performance. Similar effects can occur with the SOA in an extended cavity where the voltage on the SOA will show a modulation since the optical pulse is depleting it only part of the round-trip time.

\section{USE OF ACTIVE-PASSIVE INTEGRATION FOR MLL}

Over the last few years indium phosphide (InP) based photonic integration platforms have been established. These platforms enable complex monolithically integrated optical circuits. In a particular technology platform the composition of the layer stack is a given but a large degree of freedom in the design of the laser circuit is available to meet the application requirements. In this paper results are presented that have been obtained by the authors utilizing the standardized integration platforms on InP developed at our institute ${ }^{9,3}$ that is now used and developed further by Smart Photonics B.V. and accessible through the JePPIX brokering organization ${ }^{10}$. The platform is based on InP substrate with $\mathrm{InP} / \mathrm{InGaAsP}$ ridge waveguides. The monolithic active-passive integration in which the active areas are at the same level on the wafer is realized using a regrowth technique.

The ability to combine active and passive components in the laser cavity brings a number of aspects that can be used to improve the performance and utilization of the mode-locked laser. The first advantage is that the repetition rate of the laser which is determined by the total cavity length can become more independent from the length of the SOA and SA since part of the cavity can be a passive waveguide. In particular for cavity lengths above a few hundred microns this means that the SOA can be shorter, thus reducing power consumption and self-phase modulation effects. Another advantage is that the energy stored is lowered which will reduce low frequency fluctuations. A second point is that the relative position of the SOA and the SA can be optimized. This can be done for the largest operating range and output power ${ }^{11}$, or in a ring laser the main direction in which the laser operates can be determined ${ }^{12,13}$. A third aspect is that the output coupler structure can be passive. This is easier to fabricate and provides a better control over the coupling fraction. A fourth aspect is that other components can be added to the cavity, e.g. phase modulators, Mach-Zehnder filters or arrayed waveguide gratings for tuning or bandwidth control ${ }^{14,15}$. The last aspect mentioned here is that the lasers can be part of a larger circuit. When the cavity is a ring or when it is linear using on-chip reflectors ${ }^{16}$ the laser can be positioned anywhere on the chip so it can be combined with other more complex device. Because the output of the laser is a short pulse, non-linear effects in a series of SA/SOA sections can be used to realize on-chip isolation of the mode-locked laser against weak reflections from other elements of the circuit ${ }^{17}$. 
To illustrate several of these aspects three photonic integrated devices are discussed below in more detail. The first is a circuit with $2.5 \mathrm{GHz}$ mode-locked lasers, the second is a $7 \mathrm{GHz}$ mode-locked ring laser of which the frequency comb has been stabilized and the third is a $12.5 \mathrm{GHz}$ ring laser which demonstrated a frequency comb spanning over $40 \mathrm{~nm}$.

\section{MODE-LOCKED RING LASERS AT 2.5 GHZ}

The first device is a $2.5 \mathrm{GHz}$ extended cavity mode-locked ring laser with an off-set frequency control. Its intended use was for dual frequency comb spectroscopy ${ }^{18}$ where the two required comb sources can be integrated onto a single chip. Also the two frequency combs produced need to be stabilized with respect to each other and have a small difference in comb spacing ( 2 to $3 \mathrm{MHz}$ difference was aimed for in this particular case). The laser design is an example of how repetition rates that are relatively low for integrated mode-locked semiconductor lasers are feasible, the use of an optimized SA and SOA layout and the use of intra-cavity elements. The mask layout of the device is presented in Figure 1a. The SA is $50 \mu \mathrm{m}$ long and is surrounded by two $450 \mu \mathrm{m}$ long SOAs that are connected to the same electrical contact. The electrical isolation sections between the SA and SOA are $25 \mu \mathrm{m}$ long. The $33 \mathrm{~mm}$ long ring cavity is formed using deeply etched passive waveguides thus minimizing the footprint of an individual MLL. In the cavity are two $810 \mu \mathrm{m}$ long electro refractive modulators which can be used to precisely tune the offset frequency of the comb. A $2 \times 2$ multimode interference coupler (MMI) used for coupling out the light in both directions (50\% output coupling). The estimated round-trip passive losses in the laser cavity are at around $19.5 \mathrm{~dB}$ (taking into account typical values for optical losses of deep and shallow passive waveguides and the MMI). More details on a very similar laser with a $100 \mu \mathrm{m}$ long SA are presented in ${ }^{19}$. Two copies of the laser presented have been realized on a single chip as can be seen from a photograph in Figure 1b. The performance of the two lasers is discussed in detail in ${ }^{20}$. Typically the lasers produce a $3 \mathrm{~nm}$ wide spectrum, and 25 to $35 \mathrm{ps}$ wide autocorrelation traces. The pulses will be chirped and we expect the dispersion of the long passive waveguide starts to play a role in the laser dynamics. For stabilizing the frequency comb the comb spacing was stabilized using a stable $2.5 \mathrm{GHz}$ RF source. The laser can lock to a small range of RF frequencies which becomes wider with increasing RF power. This is depicted in Figure 1c where the integrated timing jitter over the range $(10 \mathrm{kHz}-$ $25 \mathrm{MHz}$ ) of the laser output is presented in units of picoseconds using a color scale as a function of RF frequency and power. The operating conditions where $130 \mathrm{~mA}$ total injection current and a reverse bias voltage of $-6.5 \mathrm{~V}$. The data show that the repetition rate of the laser can be tuned over a few $\mathrm{MHz}$ if sufficient RF power is applied and that the repetition rate of the lasers can be detuned from each other in this way.
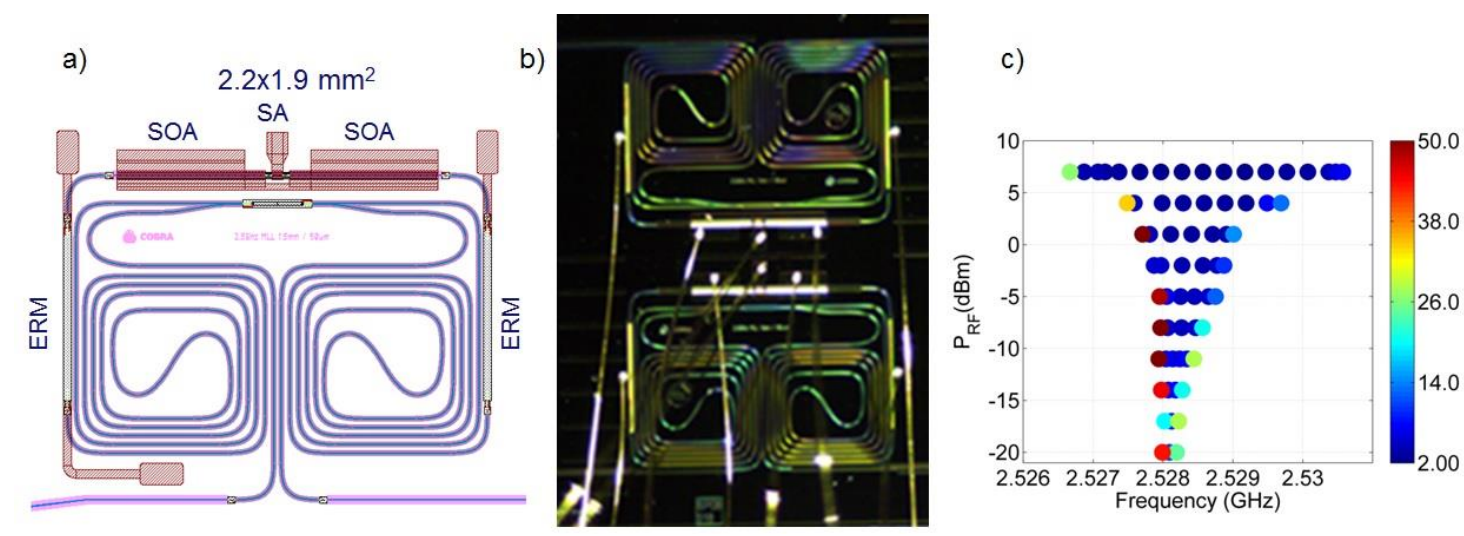

Figure 1. (a) Mask layout of the $2.5 \mathrm{GHz}$ mode-locked ring laser. The circuit dimensions are indicated. (b) Microscope photograph of the fabricated photonic integrated circuit chip with two MLLs. (c) Integrated timing jitter (range $10 \mathrm{kHz}-25 \mathrm{MHz}$ ) of the laser output in units of picoseconds using a color scale as a function of applied RF frequency $(\mathrm{GHz})$ and RF power. The operating conditions where 130mA total injection current and a reverse bias voltage of $-6.5 \mathrm{~V}$.

An interesting observation with the chip with two lasers is that when both lasers were operated and one of the lasers was stabilized using an RF signal, the other laser synchronized its output as well. This can be attributed to the physical proximity of the two SAs of the lasers and the wiring. 
When the repetition rate (the comb spacing) is stabilized using an RF signal, the offset frequency of the comb can be tuned using the ERMs in the cavity. In Figure 2a) this tuning is depicted. There the change in optical frequency of one of the modes in the comb in units of the cavity free spectral range (the laser repetition rate) is presented as a function of the applied reverse bias voltage on both ERM sections of the laser. The optical mode frequency was measured using a $20 \mathrm{MHz}$ resolution optical spectrometer. The total SOA current in $130 \mathrm{~mA}$ and the reverse bias on the SA is $-6.5 \mathrm{~V}$. The data show an unexpected response. In other devices that have been characterized the ERM gives rise to a mainly linear phase shift as a function of reverse bias voltage ${ }^{21,22}$. A linear phase delay as a function of voltage is observed only for voltages below $-6 \mathrm{~V}$ and the slope (indicated by the blue line) is then more or less the expected slope. Between 0 and -6 Volt there is no measurable response. Similar behavior has also been observed in other intra-cavity ERMs in MLLs. We attribute this to the generation of free carriers in the ERM waveguide by the optical pulse. These shield the electric field until all of the carriers are removed by the applied field. At lower voltages this seems to occurs so slow that the $20 \mathrm{ps}$ pulse has already passed the ERM which an approximate transit time of $6 \mathrm{ps.}$
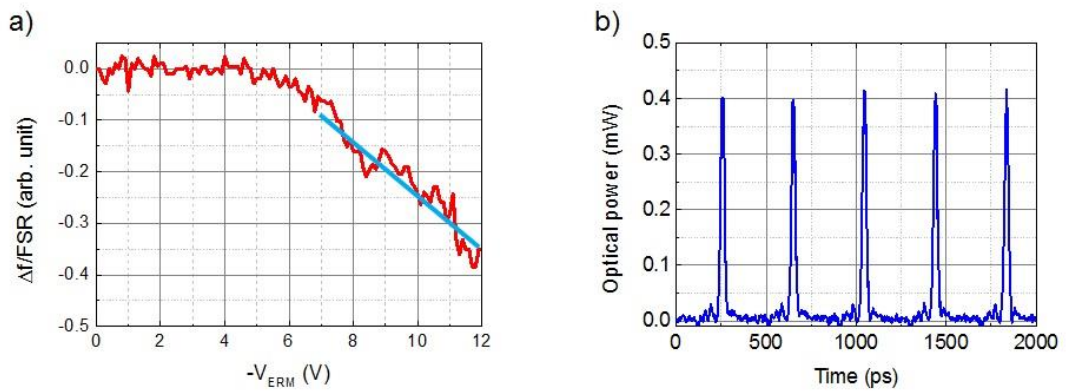

Figure 2. (a) Frequency shift of one laser mode (in units of the FSR of the laser) as a function of applied voltage to the two ERMS in the laser. The blue line indicated an expected efficiency of the ERMs. (b) Sampling oscilloscope trace of the laser output detected using a $30 \mathrm{GHz}$ bandwidth photodiode when the laser was passively mode-locked. The oscilloscope was triggered on the RF signal from the SA The operating conditions where $130 \mathrm{~mA}$ total injection current and a reverse bias voltage of $-6.5 \mathrm{~V}$.

In Figure $2 \mathrm{~b}$ a sampling oscilloscope trace is presented of the signal from a $30 \mathrm{GHz}$ analog bandwidth photodiode which detects the light of one of the $2.5 \mathrm{GHz}$ MLLs. The laser has the same operating conditions again $(130 \mathrm{~mA},-6.5 \mathrm{~V})$ but is now passively mode-locked only. The low repetition rate makes that one can clearly observe the separate pulses from the laser. Another interesting aspect is however that the sampling oscilloscope was triggered using the RF signal obtained via a bias-T from the SA of the laser. This demonstrates the RF signal one obtains from the MLL and that it can be used as well.

\section{A STABILISED 7 GHZ FREQUENCY COMB}

An actual stabilization of the frequency comb of an integrated mode-locked semiconductor laser as described in the previous section was performed using a device of which the mask layout is presented in Figure $3 \mathrm{a}$. This is a ring modelocked laser with a $7 \mathrm{GHz}$ repetition rate. The cavity has been folded for the device to fit on the chip. The laser cavity is $11.8 \mathrm{~mm}$ long with two SOAs of $455 \mu \mathrm{m}$ length around a $30 \mu \mathrm{m}$ long SA. The electrical isolation sections are $30 \mu \mathrm{m}$ long. The device also has an intra-cavity Mach-Zehnder interferometer (MZI) with a $750 \mu \mathrm{m}$ SOA in one arm and a $2200 \mu \mathrm{m}$ long ERM in the other arm. The MZI input and output components are two 2x2 MMI coupler which also act as output couplers. There are therefore two output couplers in the cavity, one for each direction. The device was originally designed to test the idea of using an intra-cavity MZI filter to flatten the gain curve in the laser as described in ${ }^{14}$. To this purpose the MZI needs a controllable modulation depth using the SOA and tuning using the ERM. The use of an SOA in the MZI inside the laser cavity give rise to very complex behavior of the device due to the interaction of the pulse in the MZI-SOA. The laser could however also be used with a reverse bias on the MZI-SOA which effectively closes this arm in the MZI. The ERM then can be used to control the cavity length for stabilization of the frequency comb. In this circuit however $50 \%$ of the light coupled out of the cavity is now deposited in the reverse biased MZI-SOA.

In Figure $3 \mathrm{~b}$ an output spectrum of the laser under mode-locking conditions is presented. The operating conditions were $-4 \mathrm{~V}$ reverse bias voltage applied to the SA, $-1.5 \mathrm{~V}$ of reverse bias voltage applied to the MZI-SOA and $71 \mathrm{~mA}$ total current to the two SOA sections. The repetition rate was stabilized using a low-phase noise RF generator. The tuning of the comb was then stabilized by mixing the output of the MLL with a stable continuous tunable single mode laboratory laser on a photodiode. The lowest RF frequency component originating from the mixing between the single mode laser 
a)

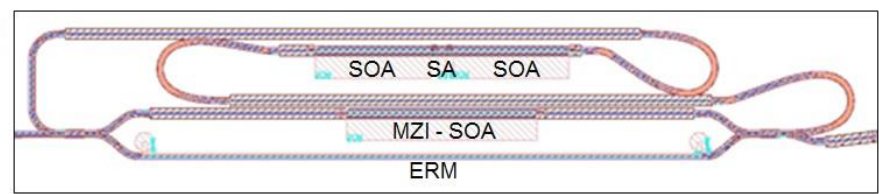

b)
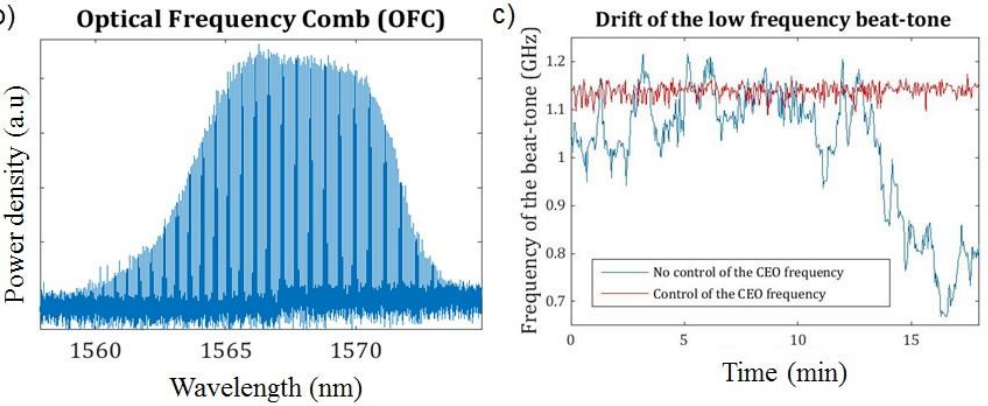

Figure 3. (a) Mask lay-out of the $7 \mathrm{GHz}$ mode-locked ring laser with an intracavity tunable MZI. (b) Output spectrum of the laser under mode-locked operation. (c) The beat tone frequency of a comb line with a tunable $\mathrm{CW}$ single frequency laser as a function of time with (red line) and without (blue line) feedback on the ERM. The operating conditions where $71 \mathrm{~mA}$ total injection current, a reverse bias voltage on the SA of $-4.0 \mathrm{~V}$ and a reverse bias voltage of $-1.5 \mathrm{~V}$ on the MZI-SOA.

and the nearest comb line was used to generate a feedback signal for the control of the ERM in the integrated laser. This work will be described in detail in a publication that is currently being prepared. The feedback system was able to keep the frequency comb locked to the tunable CW laser over minutes. This can be seen from Figure 3c. This depicts the beat frequency between the $\mathrm{CW}$ laser at $1566.576 \mathrm{~nm}$ and the nearest comb line measured using an RF analyzer as a function of time for a situation without (blue line) and with feedback (red line) to the ERM. The stability is limited by the width of the beat tone which is still several $100 \mathrm{MHz}$ wide. Some narrowing of the beat tone was observed with the feedback on but the bandwidth of the feedback loop appears to low to reduce the width of the beat frequency effectively. The integration technology used makes that the mode-locked laser and a single frequency $\mathrm{CW}$ laser to stabilize to can be easily and quickly combined on a single chip.

\section{A 42NM WIDE 12.5 GHZ FREQUENCY COMB}

The third device illustrates that using standardized basic components surprisingly interesting results can be obtained. This is a $12.5 \mathrm{GHz}$ mode-locked ring laser the mask lay-out of which is presented in Figure 4a.

a)

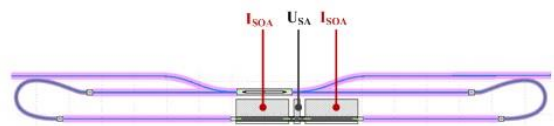

b)

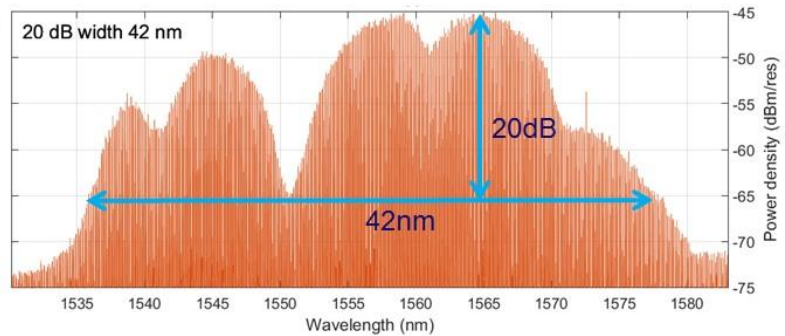

Figure 4. (a) Mask layout of a $12.5 \mathrm{GHz}$ ring laser. The cavity length is $7 \mathrm{~mm}$. (b) Output spectrum of the laser with total SOA current at $59 \mathrm{~mA}$ and $-3.4 \mathrm{~V}$ on the SA.

Only the main result is presented here, more details can be found in ${ }^{23}$ and will be published elsewhere. The ring laser has again two SOA sections of $325 \mu \mathrm{m}$ each, a $40 \mu \mathrm{m}$ SA, shallowly and deeply etched passive waveguides and a $2 \times 2$ 
MMI coupler. The total length of the cavity was $7 \mathrm{~mm}$. When the SOA current was set at $59 \mathrm{~mA}$ and the reverse bias on the $\mathrm{SA}$ at $-3.4 \mathrm{~V}$, the optical bandwidth of the optical output measured at $20 \mathrm{~dB}$ below the maximum reached $42 \mathrm{~nm}$ as shown in Figure $4 \mathrm{~b}$. This width over which we have demonstrated the spectrum to be coherent, exceeds the optical bandwidth demonstrated by quantum dash and quantum dot based mode-locked lasers ${ }^{24}$. The interesting point that this laser has relatively high peak power and from the shape of the spectrum one may infer that self-phase modulation effects are important in achieving this wide a spectrum.

\section{CONCLUSION}

In this paper we have discussed the use of active-passive integration for mode-locked InP based laser systems and have shown three devices to illustrate some of the possibilities. Clearly the integration technology can be used for further improvement. The power load on the SA in these systems is an issue, it makes the devices vulnerable and the SA reduces the efficiency of the system. The combination of quantum dash or dot lasers should be interesting to explore since single section devices based on those materials can show strong mode-locking without the use of an SA. Another direction to look at are the optically pumped semiconductor disk lasers ${ }^{2}$. One could try to move to a geometry which is similar with wider amplifier mode sizes and shorter amplifiers which should minimize self-phase modulation. Finally it appears that what we consider to be passive waveguide may need to be looked into in more detail, in particular the free carriers generated in those waveguides might lead to unwanted phase variations in the laser. These may be small but might be relevant for systems with high stability requirements.

This work was supported by the EU Seventh FP7/2007-2013 grant agreement ICT 257210 "PARADIGM", Technology foundation STW project 13533 "Compact frequency comb sources" and IOP Photonic Devices project 10016230 "Integrated Fourier Transform Spectroscopy".

\section{REFERENCES}

[1] Sibbett, W., Lagatsky, A.A., Brown, C., "The development and application of femtosecond laser systems," Optics Express 20(7), 6989-7001 (2012).

[2] Okhotnikov, Oleg G. (ed.), [Semiconductor Disk Lasers, Physics and technology], Wiley-VCH, Berlin (2010)

[3] Smit, M., Leijtens, X., Ambrosius, H., Bente, E., van der Tol, J., Smalbrugge, B., de Vries, T., Geluk, E.-J., Bolk, J., et al., "An introduction to InP-based generic integration technology," Semiconductor Science and Technology 29(8), 83001 (2014).

[4] Williams, K.A., Thompson M. G., and White, I. H., "Long-wavelength monolithic mode-locked diode lasers", New Journal of Physics 6, 179 (2004).

[5] Haus, H., "Theory of mode locking with a slow saturable absorber," Quantum Electronics, IEEE Journal of 11(9), 736-746 (1975).

[6] Loh, W., O’Donnell, F. J., Plant, J. J., Brattain, M. A., Missaggia, L. J.., Juodawlkis, P. W., "Packaged, HighPower, Narrow-Linewidth Slab-Coupled Optical Waveguide External Cavity Laser (SCOWECL)," IEEE Photonics Technology Letters 23(14), 974-976 (2011).

[7] Mandridis, D., Ozdur, I., Quinlan, F., Akbulut, M., Plant, J. J., Juodawlkis, P. W.., Delfyett, P. J., "Low-noise, low repetition rate, semiconductor-based mode-locked laser source suitable for high bandwidth photonic analog-digital conversion," Applied optics 49(15), 2850-2857 (2010).

[8] Arahira, S.., Ogawa, Y., "Repetition-frequency tuning of monolithic passively mode-locked semiconductor lasers with integrated extended cavities," Quantum Electronics, IEEE Journal of 33(2), 255-264 (1997).

[9] Erwin Bente and Meint Smit, "Ultrafast InP optical integrated circuits", Proc. SPIE 6124, Optoelectronic Integrated Circuits VIII, 612419 (March 03, 2006); doi:10.1117/12.660399.

[10] JePPIX, "Joint European Platform for InP-based Photonic Integrated Components and Circuits", http://www.jeppix.eu/.

[11] Moskalenko, V., Williams, K. A., Bente, E. A. J. M., "Integrated Extended-Cavity 1.5um Semiconductor Laser Switchable Between Self- and Anti-Colliding Pulse Passive Mode-Locking Configuration,” IEEE Journal of Selected Topics in Quantum Electronics 21(6), 1-6 (2015).

[12] Bente, E. A. J. M., Barbarin, Y., Heck, M. J. R.., Smit, M. K., "Modeling of integrated extended cavity InP/InGaAsP semiconductor modelocked ring lasers," Optical and Quantum Electronics 40(2-4), 131-148 (2008) 
[13] Tahvili, M. S., Barbarin, Y., Leijtens, X. J. M., De Vries, T., Smalbrugge, E., Bolk, J., Ambrosius, H., Smit, M. K.., Bente, E., "Directional control of optical power in integrated InP/InGaAsP extended cavity mode-locked ring lasers," Optics letters 36(13), 2462-2464 (2011).

[14] Moskalenko, V., Javaloyes, J., Balle, S., Smit, M. K.., Bente, E. A. J. M., "Theoretical Study of Colliding Pulse Passively Mode-Locked Semiconductor Ring Lasers With an Intracavity Mach-Zehnder Modulator," IEEE Journal of Quantum Electronics 50(6), 415-422 (2014).

[15]Liu, S., Wang, H., Sun, M., Zhang, L., Chen, W., Lu, D., Zhao, L., Broeke, R., Wang, W., et al., “AWG-based Monolithic 4x12 GHz Multichannel Harmonically Mode-locked Laser," IEEE Photonics Technology Letters, $1-1(2015)$.

[16] Gordón, C., Guzmán, R., Leijtens, X.., Carpintero, G., “On-chip mode-locked laser diode structure using multimode interference reflectors," Photonics Research 3(1), 15 (2015).

[17]Heck, M. J. R., Bente, E. A. J. M., Barbarin, Y., Lenstra, D.., Smit, M. K., "Monolithic Semiconductor Waveguide Device Concept for Picosecond Pulse Amplification, Isolation, and Spectral Shaping," IEEE Journal of Quantum Electronics 43(10), 910-922 (2007).

[18] Coddington, I., Swann, W.., Newbury, N., "Coherent Multiheterodyne Spectroscopy Using Stabilized Optical Frequency Combs," Physical Review Letters 100(1) (2008).

[19] Latkowski, S., Moskalenko, V., Tahvili, S., Augustin, L., Smit, M., Williams, K.., Bente, E., "Monolithically integrated $2.5 \mathrm{GHz}$ extended cavity mode-locked ring laser with intracavity phase modulators," Optics Letters 40(1), 77 (2015).

[20] Latkowski, S., Llorens Revull, M., Tahvili, S., Williams, K., Bente, E., "Integrated mode-locked InP based lasers for fourier transform spectroscopy", Proc. 17th International Conference on Transparent Optical Networks (ICTON), Tu.B5.4 (2015).

[21] Tilma, B. W., Jiao, Y., van Veldhoven, P. J., Smalbrugge, B., Ambrosius, H. P. M. M., Thijs, P. J., Leijtens, X. J. M., Noetzel, R., Smit, M. K., et al., "InP-Based Monolithically Integrated Tunable Wavelength Filters in the 1.6-1.8 mu m Wavelength Region for Tunable Laser Purposes," Journal of Lightwave Technology 29(18), 2818-2830 (2011).

[22] Tahvili, M. S., Smalbrugge, E., Leijtens, X. J. M., Wale, M. J., Smit, M. K.., Bente, E. A. J. M., “Calibration of an InP-Based Monolithically Integrated Optical Pulse Shaper,” IEEE Photonics Journal 5(6), 6602317-6602317 (2013).

[23] Moskalenko, V., Williams, K., Koelemeij, J.., Bente, E., "42 nm wide coherent frequency comb generated by a QW based integrated passively mode-locked laser," Semiconductor Laser Conference (ISLC), 2016 International, 1-2, IEEE (2016).

[24] Rosales, R., Murdoch, S. G., Watts, R. T., Merghem, K., Martinez, A., Lelarge, F., Accard, A., Barry, L. P.., Ramdane, A., "High performance mode locking characteristics of single section quantum dash lasers," Optics express 20(8), 8649-8657 (2012). 